\title{
SISTEM PENCATATAN DAN PELAPORAN TERPADU PUSKESMAS (SP2TP) DI WILAYAH DINAS KESEHATAN KABUPATEN DOMPU PROVINSI NTB
}

\author{
Nurul Dwi Suryani, Solikhah \\ Fakultas Kesehatan Masyarakat, Universitas Ahmad Dahlan Yogyakarta
}

\begin{abstract}
Absract
Background: SP2TP is to meet the needs of administration at the higher level in order to develop, determine policies and utilized by health centers to improve efforts of health centers, through planning, mobilization, execution, monitoring, control and assessment. Based on the results of the initial survey SP2TP in Dompu has not been maximal. Therefore it is necessary to study the system of integrated recording and reporting of health centers (SP2TP) in the area of health services in Dompu Regency.

Methods: This research is a qualitative descriptive located in all district health centers in Dompu Regency. Data was collected through interviews with the study subjects of ten people in the board of integrated recording and reporting system of health centers in each health center and health department.

Results: The study results indicated that the reporting was still done manually; it still focused on disease patterns and the most 10 diseases. The submitted report was incomplete because there was no coordination, guiding book, difficult transportation, electrical disturb, Feedback was given orally. In terms of data quality SP2TP was still low. This was proven by the low completeness and timeliness for report delivery. While the use of data and information was still focused on the annual profiling.

Conclusion: the difficult accessibility of health centers with the Health Service made report shipping incomplete and not timely.
\end{abstract}

Keywords: System reporting, system recording, SP2TP

\section{PENDAHULUAN}

Sistem informasi puskesmas (SIMPUS) dan sistem pelaporan terpadu SIMPUS (SPT SIMPUS) telah dikembangkan diberbagai jajaran dinas kesehatan kabupaten yang ada di Indonesia. SIMPUS merupakan perangkat lunak yang digunakan puskesmas untuk merekam data kunjungan pasien rawat jalan. Data kunjungan pasien disimpan dan digunakan untuk membuat data peleporan pada periode waktu tertentu yang selanjutnya data tersebut dikirimkan ke dinas kesehatan. Data pelaporan antar puskesmas di tingkat kabupaten memiliki struktur data yang sama. SPT SIMPUS merupakan sistem informasi yang digunakan di tingkat dinas kesehatan. Sistem ini dikembangkan untuk memenuhi kebutuhan dinas kesehatan dalam mengelola data-data yang dimiliki ${ }^{1}$.

Sistem pencatatan dan pelaporan terpadu puskesmas (SP2TP) merupakan kegiatan dan pelaporan data umum, sarana, tenaga dan upaya pelayanan kesehatan di masyarakat (SK Menkes No 63/Menkes/SK/11/1981) ${ }^{2}$. Sistem pencatatan dan pelaporan terpadu puskesmas (SP2TP) adalah tata cara pencatatan dan pelaporan yang lengkap untuk pengelolaan puskesmas, meliputi keadaan fisik, tenaga, sarana, dan kegiatan pokok yang dilakukan serta hasil yang dicapai oleh puskesmas ${ }^{3}$.

Sistem pencatatan dan pelaporan terpadu puskesmas (SP2TP) dikirim ke dinas kesehatan kabupaten atau kota setiap awal bulan. Dinas kesehatan kabupaten atau kota mengolah kembali laporan puskesmas dan mengirimkan umpan baliknya ke dinas kesehatan provinsi dan departemen kesehatan pusat. 
Feed back terhadap laporan puskesmas harus dikirimkan kembali secara rutin ke puskesmas untuk dapat dijadikan evaluasi keberhasilan program ${ }^{4}$. Jenis dan periode laporan yaitu (1) Bulanan, data kesakitan, data kematian, data operasional (gizi, imunisasi, KIA, KB, dsb.), data manajemen obat, (2) Triwulan, data kegiatan puskesmas, (3) Tahunan, umum dan fasilitas, sarana, dan tenaga ${ }^{3}$.

Pemanfaatan data sistem pencatatan dan pelaporan terpadu puskesmas (SP2TP) untuk memenuhi kebutuhan administrasi pada jenjang yang lebih tinggi dalam rangka pembinaan, penetapan kebijaksanaan dan dimanfaatkan oleh puskesmas untuk peningkatan upaya kesehatan puskesmas, melalui perencanaan, penggerakan, pelaksanaan, pengawasan, pengendalian, dan penilaian ${ }^{3}$. Selain itu berfungsi untuk petugas di tingkat puskesmas lebih bertanggung jawab dalam mencatat seluruh upaya kesehatan yang dilaksanakannya dan melaporkan secara teratur dan tepat waktu serta mampu memanfaatkan data dan informasi dari data sistem pencatatan dan pelaporan terpadu puskesmas (SP2TP) sehingga dapat memberikan umpan balik ${ }^{5}$.

Berdasarkan hasul studi pendahuluan dan wawancara dengan pengurus sistem pencatatan dan pelaporan terpadu puskesmas (SP2TP) di Dinas Kesehatan Kabupaten Dompu, yang dilakukan pada bulan Juni 2012 permasalahan yang ada di beberapa Puskesmas Dompu adalah (1) Keterlambatan dalam pengiriman laporan sistem pencatatan dan pelaporan terpadu puskesmas (SP2TP) oleh petugas puskesmas sehingga menyulitkan pencatatan; (2) Data tentang gizi, KIA, imunisasi (LB3) yang dikirim masih kurang lengkap; (3) Penanggung jawab data sistem pencatatan dan pelaporan terpadu puskesmas (SP2TP) di puskesmas pembantu tidak mengirimkan data pada dinas kesehatan; (4) Tidak ada koordinasi antara pengelola sistem pelaporan dengan petugas di puskesmas tentang waktu yang ditetapkan dalam pengiriman laporan sistem pencatatan dan pelaporan terpadu puskesmas (SP2TP). Menelaah latar belakang diatas, maka peneliti ingin mengetahui sistem pencatatan dan pelaporan terpadu puskesmas di wilayah Dinas Kesehatan Kabupaten Dompu Provinsi NTB.

\section{METODE}

Jenis penelitian ini adalah deskriptif kualitatif. Penelitian dilaksanakan di Dinas Kesehatan dan Puskesmas Dompu, Kecamatan Dompu, Kabupaten Dompu Provinsi NTB pada bulan November-Desember 2012. Objek penelitian adalah SP2TP di wilayah Dinas Kesehatan Kabupaten Dompu. Subjek penelitian dalam penelitian adalah pengurus SP2TP masing-masing 1 staf di 9 puskesmas dan 1 staf di dinas kesehatan. Alat penelitian yang digunakan dalam pengumpulan data penelitian ini adalah menggunakan pedoman wawancara dengan menggunakan metode triangulasi sumber ${ }^{6}$.

Variabel di dalam penelitian ini adlah variabel tunggal yang meliputi pencatatan, pelaksanaan, pengawasan sistem pencatatan dan pelaporan terpadu puskesmas (SP2TP) di wilayah Dinas Kesehatan Kabupaten Dompu Provinsi NTB.

\section{HASIL PENELITIAN DAN PEMBAHASAN}

\section{A. Hasil Penelitian}

Luas wilayah Kabupaten Dompu $2.324,55 \mathrm{~km}^{2}$ dengan ketinggian kota berkisar antara 15-62 meter di atas permukaan laut. Wilayah administrasi Kabupaten Dompu terbagi menjadi delapan kecamatan, dan tujuh puluh sembilan kelurahan/desa. Kecamatan Dompu yang luasnya adalah $223,27 \mathrm{~km}^{2}$, Kecamatan Woja $301,16 \mathrm{~km}^{2}$, Kecamatan Hu'u 186,50 km², Kecamatan Kempo 
$191,67 \mathrm{~km}^{2}$, Kecamatan Kilo 235,00 km², Kecamatan Pajo 135,32 km², Kecamatan Manggelewa 176,46 km², dan Kecamatan Pekat adalah kecamatan terluas yaitu 943,22 $\mathrm{km}^{2}$ dan terjauh dari ibu kota kabupaten. Sebagian besar wilayah Kabupaten Dompu merupakan dataran rendah yang digunakan sebagai lahan perkebunan, hutan, persawahan dan pemukiman. Daratan Kabupaten Dompu dialiri oleh 122 sungai yang pada umumnya dimanfaatkan untuk pengairan lahan pertanian. Kondisi geografis wilayah Kabupaten Dompu sebagian besar merupakan daerah pegunungan, perbukitan, daerah pantai dan rawa-rawa, masih banyaknya jumlah penduduk miskin dan keterbatasan kemampuan sumber daya manusia dan sumber daya lainnya.

\section{Pencatatan}

Hasil wawancara mekanisme pencatatan laporan SP2TP sebelum dikirim ke Dinas Kesehatan, diambil di masing-masing program, data kesakitan (LB1), KIA, gizi, imunisasi, P2M (LB3), dan data kegiatan puskesmas (LB4). Lalu dilengkapi oleh puskesmas baru dikirim ke dinas kesehatan setiap bulannya dan semua laporan dikerjakan secara manual.

\section{Pelaporan}

Hasil wawancara apakah laporan SP2TP yang dikirim sudah lengkap, yang dijelaskan oleh responden berdasarkan hasil wawancara laporan SP2TP yang dikirim ada beberapa yang tidak lengkap.

Hasil wawancara kesulitan yang dihadapi kaitannya SP2TP, pencatatan dilakukan secara manual, tidak ada koordinasi, keterlambatan dalam pengiriman laporan, tidak ada buku petunjuk, seperti yang dijelaskan oleh responden.

\section{Pelaksanaan}

Berdasarkan hasil wawancara dengan responden, pelaksanaan SP2TP di tingkat puskesmas adalah diketahui bahwa pelaksanaan SP2TP cukup membantu untuk mengumpulkan data karena dilaksanakan dengan baik oleh tenaga SP2TP di tiap puskesmas, meskipun ada beberapa yang mengatakan bermasalah sebagaimana hasil wawancara.

Hasil wawancara tentang upaya yang dilakukan agar pengiriman laporan SP2TP tepat waktu, sebagaimana yang dijelaskan oleh responden, karena masing-masing puskesmas selalu berusaha menghimbau secara lisan maupun dihimbau dalam setiap kegiatan seperti rapat minilokarya yang diadakan setiap bulannya, sehingga dapat dikerjakan semaksimal mungkin oleh tiap-tiap program.

\section{Pengawasan}

Hasil wawancara tentang pengawasan yang dilakukan dalam rangka menjaga kelancaran pelaksanaan sistem pencatatan dan pelaporan terpadu puskesmas (SP2TP) sudah berjalan di tiap puskesmas di Kabupaten Dompu, seperti yang dijelaskan oleh responden.

Hasil wawancara tentang apakah laporan sistem pencatatan dan pelaporan terpadu puskesmas (SP2TP) yang dikirim ke dinas kesehatan dilakukan analisis, setiap laporan yang masuk ke dinas kesehatan selalu dilakukan analisis terutama tentang adanya peningkatan kasus seperti yang dijalaskan oleh responden.

\section{B. Pembahasan}

SP2TP adalah tata cara pencatatan dan pelaporan yang lengkap untuk pengelolaan puskesmas, meliputi keadaan fisik, tenaga, sarana, kegiatan pokok yang dilakukan, dan hasil yang dicapai oleh puskesmas7. SP2TP meliputi pencatatan, pelaporan, pelaksanaan, pengawasan. Dari hasil wawancara dengan pengurus SP2TP di wilayah Dinas Kesehatan Dompu diketahui bahwa : 
1. Pencatatan

Pencatatan SP2TP ditiap puskesmas di Kabupaten Dompu diambil dari masing-masing program yaitu laporan bulanan data kesakitan (LB1), laporan bulanan pemakaian dan lembar permintaan obat (LB2), laporan gizi, KIA, imunisasi dan pemberantasan penyakit menular (LB3), serta laporan bulanan kegiatan puskesmas (LB4) dan dilengkapi oleh puskesmas baru dikirim ke dinas kesehatan setiap bulannya tiap tanggal 10 dan semua laporan dikerjakan secara manual. Pencatatan seperti itu sangat kurang efisien karena ada kesulitan menunggu kecepatan pengumpulan laporan dari teman-teman program KIA, gizi, imunisasi, semua program puskesmas dan mempersulit petugas dan kelemahannya data tentang kesehatan tidak menyeluruh, koordinasi antar tim kesehatan tidak ada, dan layanan kesehatan yang tuntas sulit dilakukan. Setiap petugas kesehatan dituntut membuat pencatatan yang baik, sistematis, jelas, ringkas, dan mengacu pada intervensi yang diberikan tentang data kesehatan².

Kegiatan program akan menghasilkan data. Data perlu dicatat, dianalisis dan dibuat laporan. Data adalah data siap pakai sehingga dapat dipresentasikan dalam bentuk tabel, grafik, atau dilaporkan dalam bentuk naratif. Data yang disajikan tersebut adalah informasi tentang pelaksanaan program dan perkembangan masalah kesehatan masyarakat agar menjadi pengetahuan bagi semua staf puskesmas ${ }^{4}$.

2. Pelaporan

Pelaporan SP2TP yang dilakukan dan dikirim sudah lengkap, tapi ada beberapa yang tidak lengkap, permasalahannya adalah keterlambatan pengiriman laporan dari puskesmas pembantu karena tidak ada koordinasi tentang waktu dalam pengumpulan laporan, tidak ada buku petunjuk, masalah transportasi, mati lampu, tidak ada honor khusus. Data dan informasi yang lengkap sangat dibutuhkan oleh tiap pengguna informasi dengan adanya keterlambatan mempengaruhi tepat tidaknya keputusan yang dibuat oleh para pengambil keputusan karena sangat bergantung dari informasi yang didapat dan informasi yang dihasilkan tidak lengkap dan salah maka pengambilan keptusan akan menjadi tidak tepat dan salah sasaran. Data dan informasi yang lengkap akan membantu dalam pengambilan keputusan yang tepat dan bermanfaat baik jangka pendek maupun jangka panjang ${ }^{8}$.

Pelaporan adalah lebih bersifat objektif yang dilaporkan terinci dan disampaikan secara jelas dan lengkap. Pelaporan merupakan cara komunikasi petugas kesehatan tentang hasil suatu kegiatan yang telah dilaksanakan dan pelaporan sebagai alat komunikasi yang penting antar petugas kesehatan dalam melakukan kegiatan ini diperlukan data informasi yang tepat, akurat, tanpa adanya hal tersebut kegiatan pelaporan akan diragukan kebenarannya ${ }^{3}$.

1. Laporan bulanan data kesakitan (LB1), laporan bulanan pemakaian dan lembar permintaan obat (LB2), laporan gizi, KIA, imunisasi dan pemberantasan penyakit menular (LB3), serta laporan bulanan kegiatan puskesmas (LB4).

2. Laporan tahunan data dasar (LT1), laporan tahunan data kepegawaian (LT2), dan laporan tahunan data peralatan (LT3) ${ }^{5}$.

3. Pelaksanaan

SP2TP harus dikirim paling telat tanggal 10 ditiap bulannya ke Dinas Kesehatan, yang dilakukan dan dikirim oleh Puskesmas ke Dinas Kesehatan pengiriman laporan sebelum tanggal 10 ditiap bulannya. Pelaksanaan SP2TP di Puskesmas Kabupaten Dompu cukup membantu 
untuk mengumpulkan data karena dilaksanakan dengan baik oleh tenaga SP2TP di tiap puskesmas dan tepat waktu dalam pengiriman ke Dinas Kesehatan karena dikirim sebelum tanggal 10 ditiap bulannya dan masingmasing puskesmas selalu berusaha menghimbau secara lisan maupun dihimbau dalam setiap kegiatan seperti rapat minilokakarya yang diadakan setiap bulannya. Pelaksanaan SP2TP berdasarkan keputusan Direktur Jendral dalam pelaksanaan pembinaan Kesehatan Masyarakat nomor 590/BM/DJ/INFO/V/1996 tentang penyederhanaan SP2TP, formulir laporan telah disederhanakan dalam upaya untuk mengurangi beban kerja bagi petugas puskesmas, diharapkan tidak adanya laporan lain dari puskesmas selain SP2TP, dan data atau variabel yang dilaporkan diharapkan dapat dipercaya serta dapat diterima tepat waktu ${ }^{5}$.

Tujuan dari sistem pencatatan dan pelaporan terpadu puskesmas yaitu, tersedianya data (keadaan fisik, tenaga, sarana, dan kegiatan pokok puskesmas yang akurat, tepat waktu, dan mutakhir secara teratur), terlaksana pelaporan data tersebut secara teratur di bergagai jenjang administrasi sesuai dengan yang berlaku, pemanfaatan data tersebut untuk pengambilan keputusan ${ }^{\text {. }}$.

4. Pengawasan

Pengawasan yang dilakukan pada SP2TP sudah berjalan di tiap puskesmas di kabupaten dompu karena setiap laporan yang masuk ke dinas kesehatan selalu dilakukan analisis oleh pengurus SP2TP di Dinas Kesehatan terutama tentang adanya peningkatan 10 kasus penyakit, walaupun sudah adanya analisis dari Dinas Kesehatan dan pengawasan oleh Kepala Puskesmas, laporan SP2TP yang dikirim ke Dinas Kesehatan tetap memiliki permasalahan terutama tentang kelengkapan laporan yang dikirim oleh puskesmas, Pengawasan adalah melakukan penilaian dan sekaligus koreksi terhadap setiap penampilan pegawai untuk mencapai tujuan yang telah ditetapkan dalam rencana atau suatu proses untuk mengukur penampilan suatu program yang kemudian dilanjutkan dengan mengarahkannya sehingga tujuan yang telah ditetapkan dapat tercapai, pengawasan dengan menggunakan pengukuran hasil kinerja aktual pegawai yaitu:

1. Pengamatan (observasi) secara pribadi yang dilakukan pimpinan yang memantau aktivitas pegawai di wilayah kerja puskesmas.

2. Laporan lisan dapat berupa wawancara, pertemuan kelompok. mengandung kelebihan tertentu karna informasi ditransisi secara lisan dan di dalamnya terdapat kontak pribadi.

3. Laporan tertulis digunakan untuk memperoleh keterangan atau hasil pekerjaan yang mencakup data yang komprehensif dan bermanfaat untuk penyusunan statistik.

4. Inspeksi dengan menggunakan pembanding kualitas pelayanan kesehatan dengan standar layanan kesehatan ${ }^{9}$.

\section{SIMPULAN DAN SARAN}

\section{A. Simpulan}

Berdasarkan hasil penelitian yang dilakukan, maka proses kegiatan sistem pencatatan dan pelaporan terpadu puskesmas (SP2TP) yang ada di tiap Puskesmas Kabupaten Dompu dapat disimpulkan sebagai berikut: 
1. Pencatatan

Pencatatan pada laporan sistem pencatatan dan pelaporan terpadu puskesmas (SP2TP) semua puskesmas di Kabupaten Dompu dalam pekerjaannya masih bersifat manual.

2. Pelaporan

Pelaporan pada sistem pencatatan dan pelaporan terpadu puskesmas (SP2TP) masih belum lengkap karna tidak ada koordinasi, tidak ada buku petunjuk, sulit transportasi, mati lampu, tidak ada honor khusus.

3. Pelaksanaan

Pelaksanaan pada sistem pencatatan dan pelaporan terpadu puskesmas (SP2TP) masih ada yang bermasalah karena belum lengkap dan belum tepat waktu dalam pelaporannya.

4. Pengawasan

Pengawasan pada sistem pencatatan dan pelaporan terpadu puskesmas (SP2TP) sudah dilakukan di tiap puskesmas di Kabupaten Dompu karena setiap laporan yang masuk ke dinas kesehatan selalu dilakukan analisis tapi tidak dapat membantu dalam kelengkapan laporan yang dikirim oleh puskesmas.

\section{B. Saran}

Dari hasil kesimpulan sistem pencatatan dan pelaporan terpadu puskesmas (SP2TP) maka saran yang diberikan adalah buku petunjuk pemanfaatan dan pengolahan SP2TP, tiap puskesmas agar menerapkan aturan-aturan yang ada seperti pelaksanaan sistem pencatatan dan pelaporan terpadu puskesmas (SP2TP) berdasarkan keputusan Direktur Jendral dalam pelaksanaan pembinaan Kesehatan Masyarakat nomor 590/BM/DJ/INFO/V/1996 tentang penyederhanaan SP2TP dengan adanya buku petunjuk pekerjaan akan lebih efektif dan efisien.

\section{DAFTAR PUSTAKA}

1. Wijaya, R.R., Ifada, N., Achmad, J., "Perancangan dan Pengembangan Sistem Pelaporan Terpadu Sistem Informasi Puskesmas (SPT SIMPUS) Dengan Metode BPR", Jurnal Ilmiah Kursor, 5. Hal. 94, 2009.

2. Rajab, W., Epidemiologi Untuk Mahasiswa Kebidanan, Edisi pertama, EGC, Jakarta. Hal. 166-169, 2009.

3. Effendy, N., Keperawatan Kesehatan Masyarakat, Edisi kedua, EGC, Jakarta. Hal 185-187, 1998.

4. Muninjaya, A.A., Manajemen Kesehatan, Edisi kedua, EGC, Jakarta. Hal. 96,139,162. 2004.

5. Departemen Kesehatan RI, Petunjuk Pengolahan dan Pemanfaatan Data SP2TP. Jakarta. Hal. 1-3, 1997.

6. Sugiyono, Metode Penelitian Kuantitatif Kualitatif dan $R \& D$, Alfabeta, Bandung. Hal. 241, 274, 2011.

7. Purwandari, A., Ilmu Kesehatan Masyarakat Dalam Konteks Kebidanan, EGC, Jakarta. 44-45, 2011.

8. Muljo, H.H., Setiawan, J., Darmadi, H., "Sistem Informasi Pelayanan Puskesmas Terpadu", Jurnal Piranti Warta, 11. Hal. 357, 359, 2008.

9. Sulaeman, E.S., Manajemen Kesehatan, Edisi kedua, Universitas Gajah mada, Yogyakarta. Hal. 46, 307, 2011. 